\title{
SUSTAINABLE TOURISM DEVELOPMENT PLANNING IN KLONG-BLAB VILLAGE, SURAT THANI PROVINCE THAILAND
}

\section{URAI BUTTHONGDEE}

\begin{abstract}
:
The objective of the research aims to develop the route of attraction at Klong-Blab. Sustainable Tourism Development Planning (ACTPPR: 2006) In which the research shown that in the area particularly, Doi Sathit is full of natural resources. This research has 3 main objectives, they are: to study the involvement of community management, to evaluate the potential of the tourism community, and to determine the potential for tourism development.

The 400 questionnaires were completed by three sample groups: 100 locals, 20 academics, 280 tourists. The questionnaire was created to examine readiness of Doi Sathit area for tourism development and to examine weaknesses, strengths, opportunities and obstacles, of which to the development of Klong-Blab village as a tourist attraction, in order to guide the tourism development in the Klong-Blab village.

Results found that the way to the development of tourist attraction of Klong-Blab village are: Tourism Resource Development, Tourism Marketing Development, and Tourism Readiness Development. For evaluation the potential of Doi Sathit to become a part of tourist attraction sights of Klong-Blab village, by interview locals and inside observation. In addition to that there are 5 community groups meeting for the share of responsibilities which the interpretation given to the 5 areas: The center of the sufficiency economy; Non-toxic orchard; The center of a 'Lhoom' pig farm and mushroom farm; Community of learning center; and Doi Sathit Herbal Learning Center. In conclusion, these 5 areas were then a single local tourist attractions, now they become Klong-Blab community tourist attraction.
\end{abstract}

\section{Keywords:}

Potential of tourism, Herbal learning center, Lhoom pig farm, Sustainable route

JEL Classification: 029

\section{Authors:}

URAI BUTTHONGDEE, Suratthani Rajabhat University Thailand, Thailand, Email: aubuttongdee88@gmail.com

\section{Citation:}

URAI BUTTHONGDEE (2015). Sustainable Tourism Development Planning in Klong-Blab village, Surat Thani Province Thailand. International Journal of Social Sciences, Vol. IV(3), pp. 20-29., 10.20472/SS.2015.4.3.002 


\section{Introduction}

At the end of the Second World War, tourism began to flourish and spread to all corners of the world, made possible in part by higher levels of affluence (Dallen J. Timothy \& Stephen W.BOYD :2006). The objective of this study is to analyse, For the reason to study in Sustainable Tourism Development Planning in Klong-Blab village, Because in this place be permeated of tourism natural resource. For example is an invaluable heritage of the country is attracting the attention of tourists, both natural and cultural attractions, An assortment of tourism resources, there are many aspects to the criteria used to divide and resource utilization. They can search by tourism resources into three kinds of tourism resources of natural scenery, wildlife and vegetation, climate natural phenomena. The second type is tourism resources of historic and archaeological artifacts was last type is the type of culture and tourism resources, Then should to develop and planning at Klong-Blab (Jaeho Kim,Byunggook Kim,Sukhee Park:2013). Sustainable tourism-one market tool that potentially supports biodiversity servicesaims to balance the environmental, economic, and socio-cultural features of tourism development by maintaining environmental resources, the socio-cultural livelihoods of host communities, and providing stakeholder benefits (WTO, 2004), (Catherine Schloege: 2008).

In former times Surat Thani Province Is an area of natural resources with a view wildlife species and the climate is suitable for development as a tourist attraction and communities to generate income and to develop sustainable tourism. The development of tourism potential to the source (PCTPPR:2006). The Important thing is arrangement and sustainable development for give a result and benefit at this place. This research is qualitative and quantitative research. Consist of participation based on base of the driving force to strengthen community of KlongBlab's conquest. Tourism development planning must be to create a strong sense of community. The participation of the community in the development of tourism potential, Which is on the foundation of existing social capital (Foster,D.L.:1994). The Autonomous Community Confidence can learn about life on the base of lifelong learning within the context of changes that the community has the ability to alter the way of life intentionally. The principle is central to the development and strengthening of the Polish parish communities dominate. Community is important in understanding the formation of the social economy, from past to present. It is a major development and a solution to the most basic level of society. According to the concept of sustainable tourism management can conclude that. Travel Management is a leading resource for sustainable tourism (Barbosa,G.S.\& Drach,P.R.\& Corbella,O.D.:2014) to maximize the benefits. Both the benefits to be gained by the tourists and tourism resources, maintaining the appeal has not diminished. And updated service changes are always without compromise to the environment, society and culture and a key 6 things that make up the concept of management, sustainable tourism is tourism management at local and regional level, taking part.Participation of local people, the extent of tourism development, the use of local materials and production, income distribution, employment (Lisa Ruhanen.:2008)

The concept of sustainable tourism management. Such a concept can be developed into a residential area canal defeat sustained by the main tourist area development approach was used, and the resulting benefits to more areas.

\section{Objectives}

1. To study the involvement of community management

2. To evaluate the potential of the tourism community

3. To determine the potential for tourism development 


\section{Literature Review}

Bernadette Quinn (2009) did a study in problematising 'Festival Tourism': Arts Festivals and Sustainable Development in Ireland. This paper problematises the term 'festival tourism'. It conceptualises festivals as socially sustaining devices and argues that while they frequently function as tourist attractions, their social significance extends far beyond tourism. Using empirical material gathered in two case study arts festivals in Ireland, the paper demonstrates how festivals can contribute to arts development by inter alia creating demand for the arts, enhancing venue infrastructures, encouraging local creativity and animating local involvement. The paper contends that arts festivals, irrespective of their initial objectives almost inevitably develop tourist profiles over time and it proceeds to examine how changing tourism priorities in the two festivals studied impact upon sustainable festival practices. The findings suggest that tourism emerged as a key force promoting festival growth and expansion. It was found to be associated with increased revenue flows but also with increased arts activity on a year-round basis and with an improved venue infrastructure in both places. However, problems were identified with respect to the quality of the relationship forged between the festivals and local populations in the respective places. The paper concludes by arguing that festivals' engagement with tourism needs to be carefully managed in the interests of promoting the socially sustaining function of festivals and of encouraging sustainable approaches to tourism development.

Barbosa,G.S. Barbosa, G. S.\& Drach, P. R. \& Corbella, O. D. (2014) The objective of the research aims to develop a theoretical study with different positions on the terms sustainable development and sustainability. Although fairly debated and accepted by common sense, the concept of sustainability does not have precision and ends up acquiring various senses, sometimes contradictory. The distinct ideological perceptions of environmental issues translate into different discourses. Each social sector presents its position on the "environmental crisis", some catastrophic other weighted, some guiding solutions inside the current economic and social system and others suggesting drastic changes. In this context, and especially in the last three decades, the ideas of sustainable development (SD) and urban sustainability began to be discussed more intensively seeking possible solutions to urban and environmental problems

Dallen J. Timothy , Stephen W. Boyd (2006) did a study : Heritage Tourism in the $21^{\text {st }}$ Century : Valued Traditions and New Perspectives . at the and of the second world war, Tourism began to flourish and spread to all corners of the world, made possible in part by higher levels of affluence, record advancements in transportation and telecommunications technology, and enhanced international relation. Since that time, Tourism has proved many times over to be one the most powerful economic, social, cultural, ecological and political forces in the world today. It touches every nation and community, either or indirectly, even where tourism does not exist, Heritage of tourism, Which typically falls under the purview of cultural tourism, is one of the most notable and widespread types of tourism and is among the very oldest forms of travel. As history shows, even the ancient Egyptians and Romans, as well as the nobility of medieval times, traveled to experience historic places of cultural importance (Towner,1996) .

Jaeho Kim,Byunggook Kim,Sukhee Park (2013) The effects of tourism Ritualization ,Ritual Performance on Tourist ,Satisfaction : The purpose of this study was to examine the relationships between the ritualization of tourism, ritual performance, and tourist satisfaction. A total of five hundred and seventy-two tourists at cultural heritage places were invited to participate in this study. Results from this study demonstrated that the relationships between the ritualization of tourism destination and tourist behavior, ritual performance, and satisfaction to the tourist in the proposed model are relatively acceptable. Supporting the relationships is an important contribution in the sense that tourism ritualization might have various direct and indirect effects on tourist satisfaction through ritual performance at cultural heritage places. Findings from this study have indicated that the ritualization of tourism behavior may play a more important role in 
understanding the satisfaction of the cultural heritage tourist than ritualization of the tourism destination. As tourist behavior may be ritualized, tourists can be satisfied at the destination. Future studies need to identify the impact of heritage tourism experiential programs and levels of participation on ritual performance at a cultural heritage place.

Gareth Shaw, Sheela Agarwal, Paul Bull, (2010) did a study : Tourism consumption and tourst behabiour : a British perspective : Tourism consumption and tourist behaviour are important but somewhat neglected topics in the geography of tourism. This paper provides the first review of British material on these topics and attempts to position the contributions of geographers within a wider multidisciplinary framework. It considers tourist motivation and decision-making along with the impact that tourists have on local communities. This paper to studies of demand and,more especially, patterns of tourist behaviour have been wide ranging and numerous. However, the work of geographers has,to a significant degree,been interdisciplinaty and often reliant on the theoretical underpinnings of sociologists and psychologists. This is certainly the case in the understanding of tourist demand and tourist typologies (.Cohen :1984) The ling have also been continued through the influential work of Urry; first in terms of his conceptualization of the tourist.

Tsung-Chiung (Emily) Wu, Geoffrey wall and Liang-Ying Tsou (2014) did a study : Serious tourists: a proposition for sustainable indigenous tourism. This article proposes serious tourist as an approach that has the potential to assist in the development of sustainable indigenous tourism. Many indigenous places have reformed their economies by introducing tourism with ethnic culture as the core attraction. However, many have experienced adverse consequences, resulting in threats to the sustainability of indigenous communities. The main debates over sustainable indigenous tourism involve tensions and disputes regarding culturally appropriate development and economic gains. A serious tourist approach can contribute to the achievement of these dual goals of sustainable development. Visitors with a serious approach towards indigenous tourism will more likely express economic support for indigenous culture by spending on culture-related products and services. Likewise, serious travellers will reveal their respect and support for indigenous culture by seeking authentic experiences and donating to cultural conservation. These propositions regarding serious travellers are assessed and confirmed in the context of an indigenous destination in Taiwan.

Ziene Mottiar (2009) did a study in sustainable tourism comprises economic, social and environmental aspects, economic analysis has been less evident in the literature. This paper takes an economic perspective to evaluate the contribution of holiday home owners to a local economy. Tourism destinations which are at the mature stages of the tourism lifecycle wish to maximise revenue from tourism while minimising costs such as overcrowding. A prime objective has to be to attract the more economically valuable tourists. In this paper an analysis of North Wexford in Ireland poses questions such as: How does the holiday home owners' expenditure in the local area compare to that of traditional tourists? Do they purchase different types of goods? What levels of local expenditure do holiday home owners engage in for the upkeep or development of their second properties? What are the implications of these findings? The results show that there are clear economic benefits for an area that people deem attractive enough to build or purchase a holiday home in. This type of tourist has a high annual spend relative to other tourists and much of this expenditure seems to be concentrated in the local area. These findings need to be incorporated into the broader debate regarding the advantages and disadvantages of holiday home owners and the possibility of them comprising a route to sustainable development for local tourist areas. 


\section{Research Methodology}

\subsection{To collect information from the history documents.}

4.2 Oral tradition and participant and non participant Observation.

4.4 The semi-depth interviews and key informant interviews. And focused on the narrative In interviews using open-ended questions.

4.5 Normal discussion focus group and collect information from the community forum. By providing a platform for information processing and learning including articulation is that productivity and results.

4.7 This resources are the common peoples, Local intellectual community leaders, elders, leaders naturally, Political leaders, business groups and key informants .

\section{Results}

Klong-Blab village is a good place for tourist. This place is a group of community enterprises. The principle of sufficiency economy Living in Moo 5 at Surat Thani Province Thailand. Tourists are thinking about forest conservation and herbs and living by the principles of sufficiency economy initiative (Bill Bramwell:1983). The garden mix, The main crops grown fruit. Along with the herbs with also a hibiscus. To help cover the sun with herbs and served with grass sod hold later in 2004 started a group named Herbal Group Thailand. Nature and Environment and subsequently registered as a community enterprise (Bhatia,A.K.:1983). They has a membership of about 30 people by setting up a learning center with an area of 35 hectares within harbors mountain herbs, garden consists of plants. And herbs, including more than 200 species in the area are built for steam service to tourists with such requirements. In addition, the knowledge of nature tourism activities in the area, you can also do other things such as travel, tourism, and nature study (Gareth Shaw, Sheela Agarwal, Paul Bull :2010). The area has a different origin, Whether the Herbs and many other garden plants for travelers interested in ecotourism and environment. Also, the knowledge of herbs that are beneficial to health, but Thailand herb garden is also one of the attractions to the visitor gets the pleasure for body and soul back. This research was conducted qualitative and quantitative research (Howell,D.W :1989). And participation based on the belief that cooperation is the driving force to strengthen community Canal conquest. To develop the tourism potential to create a strong sense of community. The participation of the community in the development of sustainable tourism (Charuai Suwanbamrung , Somjit Promsupa, Teera Doungsin and Supapon Tongjan:2013) the local community beat canal. This can be opened as a tourist attraction. On the basis of the existing social capital is tourism resources. 


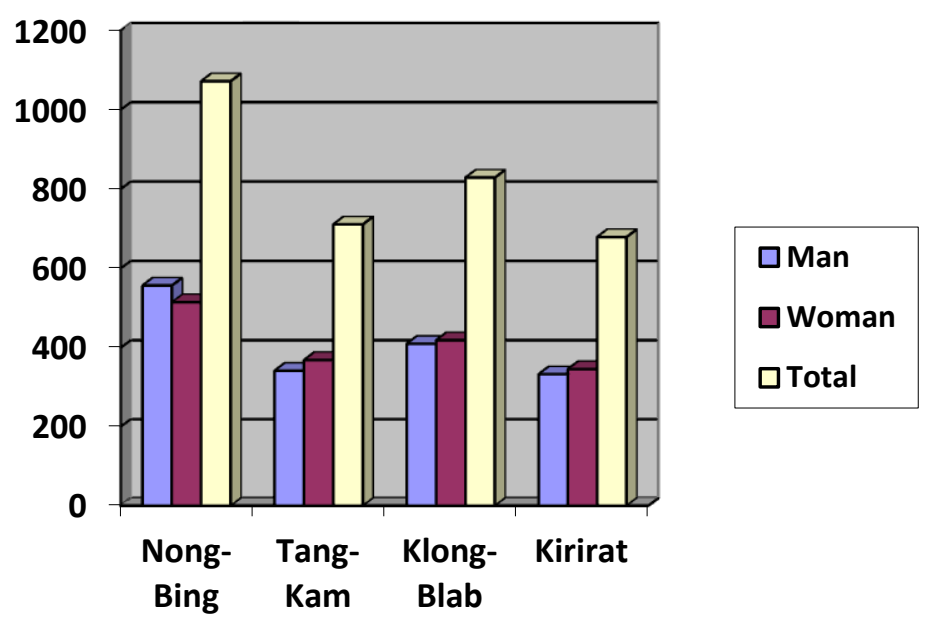

Figure 1: Table to compare the tourist 4 villages

The Autonomous Community have confidence in yourself to learn to live on the base of lifelong learning within the context of changes that the community has the ability to alter the way of life intentionally. Based community centers to improve the quality and strength of the community Canal conquest. Housing is important in understanding the formation of the social economy, from past to present. Housing is a major development and a solution to the most basic level of society. The village has a potential inherent potential and resources. Social systems and intelligence of the people. Housing developments are causing consciousness to develop by itself and the basis for the restoration of their cultural roots are firm to lead a life with dignity and live together happily. The best of communities must encourage collaborative learning community of practice to be strong and able to take care of themselves. Such as ,to promote learning between the old knowledge available in the community and strengthening of new knowledge. We have to focus on learning is combined with practice and to develop highly integrated because everything is interrelated and impact to all the laws of nature.

A set of guidelines for developing the tourism potential (Argyll and the Isles Enterprise :2000) of the community must take hold of the canal principles for sustainable tourism, which is exactly 18 below. The involvement of the community, The cooperation of the various groups involved, The creation of quality employment opportunities, Distribution of benefits from tourism, resource utilization and value. Maximum benefit, long-term planning, the balance between the economic, social, cultural, environmental, consistency between the various plans and development plans, cooperation between policy makers and practitioners. , Cooperation between tourist destinations and operators, to assess the impact of tourism. , Creation of assessment criteria, highlighting the benefits the community. Valuable natural and cultural, educational and developmental programs, strengthening features (Nisa Chatkul:2011). Ego appearance of the community and area, Regardless of their capacity to absorb resources, preservation of natural and cultural heritage resources, marketing, sustainable tourism. A set of guidelines for developing the tourism potential of the community must seize the canal principles for sustainable tourism, which is exactly 18 below. The involvement of the community, the cooperation of the various groups involved, the creation of quality employment opportunities, distribution of benefits from tourism, resource utilization and value. Maximum benefit, long-term planning, the balance between the economic, social, cultural, environmental, consistency between the various plans and development plans, cooperation between policy makers and practitioners. , Cooperation between tourist destinations and operators, to assess the impact of tourism. , Creation of 
assessment criteria, highlighting the benefits the community. Valuable natural and cultural, Educational and developmental programs, strengthening features. Ego appearance of the community and area, Regardless of their capacity to absorb resources, preservation of natural and cultural heritage resources, marketing, sustainable tourism.

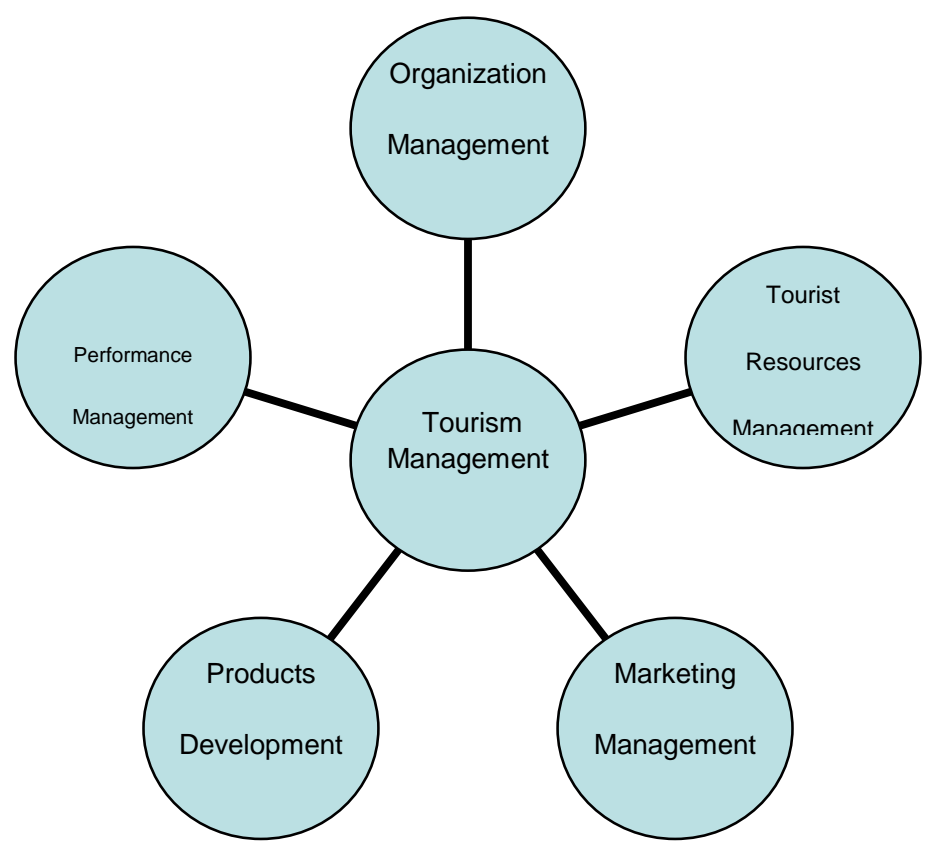

Figure 2 : Tourism Administrative Management Framework 

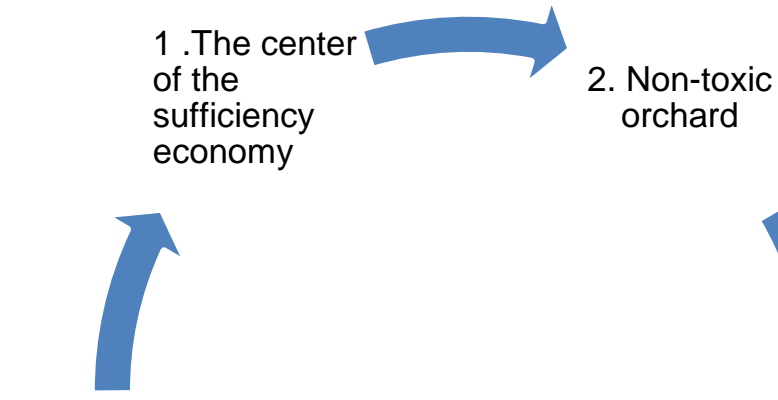

\section{Doi Sathit \\ Herbal \\ Learning \\ Center}

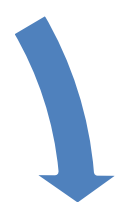

3.. The center of a 'Lhoom' pig and mushroom farm
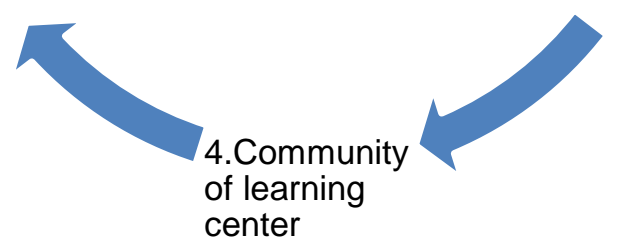

center

\section{Figure 3: Route of attraction at Klong-Blab village}

The route of attaction at Klong-Blab village are 5 areas, The first is center of the sufficiency economy, The second is Non-toxic orchard, The third is center of a 'Lhoom' pig and mushroom farm,The forth is Community of learning center and Doi Sathit Herbal Learning Center is the last attraction. In conclusion, these 5 areas were then a single local tourist attractions, now they become Klong-Blab community tourist attraction.

Theory and research results related to the development of the tourism potential of the Polish community Canal. Surat Thani Province is framework for studying the situation of tourism and community context. That can be the basis for management and development of the area. Then the next step will be to study the potential of community management of tourism. Including survey community resources into the area (Hoskin,J:1989). The data will be analyzed to make more informed management planning sessions to provide a better understanding of community based tourism. Optimized and understand the principle of attraction effectively. And the next step is to prepare the development of the community (Ziene Mottiar:2009). By conduction the knowledge of tourism in the approach to sustainable tourism development apply to human resources and development of the tourism community. When it is determined in the knowledge they bring knowledge into practice.

During the introduction of knowledge into practice, then take the results to be finalized and revised. The introduction of knowledge can be put to practical use, and efficient and effective as possible (Anne-Mette Hjalager:2008). 


\section{References}

Anne-Mette Hjalager, Comsumerism and Sustainable Tourism, Journal of Travel \& Tourism Marketing, (2008).

Argyll and the Isles Enterprise,Argyll, the Isles Lomond, Stirling and the Trossachs Tourist Board, Argyll and Bute Council,Scottish Tourist Board and Highlands and Islands Enterprise, Mull visitor surway. Edinbursh : System Three, (2000).

Asian Center for Toutism Planning and Poverty Reduction, Guidelines on Integrated Planning for sustainable tourism development,(2006)

Barbos,G.S.\& Drach,P.R.\& Corbella,O.D. A Conceptual Review of the Terms Sustainable Development and Sustainability : International Journal of Social Sciences,(2014)

Bernadette Quinn, Asian Pacific Journal of Tropical Medicine, Problematising 'Festival Tourism': Arts Festivals and Sustainable Development in Ireland. Serious tourists: a proposition for sustainable indigenous tourism (2009).

Bill Bramwell, Rural tourism and sustainablerural tourism, Journal of Sustainable Tourism, (2009).

Bhatia,A.K. (1983) . Tourism Deverlopment. New Dehil: Stering.

Catherine Schloege, Sustainable,Journal of Sustainable Forestry (2008).

Charuai Suwanbamrung, Somjit Promsupa, Teera Doungsin and Supapon Tongjan. Risk factors related to dengue infections in primary school students:Exploring students'basic knowledge of dengue and examining the lar indices in southern Thailand .Journal of Infection and Public Health (2013).

Dallen J. Timothy ,Stephen W. Boyd ,Journal of Heritage Tourism,Heritage Tourism in the $21^{\text {st }}$ century :Valued Traditions and New Perspectives. (2006).

Foster,D.L. , First Class : An Introduction to Travel and Tourism. New York : McMillann And McGraw Hill, (1994).

Gareth Shaw, Sheela Agarwal, Paul Bull, Tourism consumption and tourist behaviour : British Perspective : Touriam Geographies , (2010) .

Jaeho Kim,Byunggook Kim,Sukhee Park, The effects of Tourism Ritualization,Ritual Performance on Tourist Satisfaction. Journal of Quality Assurance in Hospitality \& Tourism, (2013).

Lisa Ruhanen, Progressing the Sustainability Debate: A Knowledge Management Approach to Sustainable Tourism Planning, Current Issues in Tourism, (2008).

Nisa Chatkul, Tourism Industry, Universiti of Julalong khron, Bangkok , (2011).

Tsung-Chiung (Emily) Wu, Geoffrey wall and Liang-Ying Tsou, Serious tourists: a proposition for sustainable indigenous tourism , Journal of Sustainable Tourism,(2014).

Ziene Mottiar , Holiday Home Owners, a Route to Sustainable Tourism Development?

AnEconomic Analysis of Tourist Expenditure Data, Journal of Sustainable Tourism (2009).

Hoskin,J., Hotel Innovation : Hi-Tech Ploy a new Landmark. Business Traveller. (February) Hongkong : Interasia Publication, (1989).

Howell,D.W, An Introduction to the Travel Tourism Industry, Ohio:South-Western Publishing, (1989).

Ziene Mottiar, Holiday Home Owners, a Route to Sustainable Tourism Development? An Economic Analysis of Tourist Expenditure Data. Journal of Tourism: (2009). 